\title{
Developing a Learning Outcome-Based Question Examination Paper Tool for Universiti Putra Malaysia
}

\author{
Sa'adah Hassan ${ }^{1}$, Novia Indriaty Admodisastro ${ }^{1}$, Azrina Kamaruddin ${ }^{1}$, Salmi Baharom ${ }^{1} \&$ Noraini Che $\mathrm{Pa}^{1}$ \\ ${ }^{1}$ Faculty of Computer Science and Information Technology, Universiti Putra Malaysia, Malaysia \\ Correspondence: Sa'adah Hassan, Faculty of Computer Science and Information Technology, Universiti Putra \\ Malaysia, 43400 UPM Serdang, Selangor, Malaysia. E-mail: saadah@upm.edu.my
}

\author{
Received: January 4, 2015 Accepted: September 11, 2015 Online Published: January 25, 2016 \\ doi:10.5539/ies.v9n2p132 URL: http://dx.doi.org/10.5539/ies.v9n2p132
}

\begin{abstract}
Much attention is now given on producing quality graduates. Therefore, outcome-based education (OBE) in teaching and learning is now being implemented in Malaysia at all levels of education especially at higher education institutions. For implementing OBE, the design of curriculum and courses should be based on specified outcomes. Thus, the challenge for the assessment is that it should be capable of measuring whether intended outcomes have been achieved or not. Likely, by assisting lecturer in preparing examination paper that aligns with the specified outcomes is something that can help to ensure the implementation of OBE. Hence, this paper describes the development of a tool for generating question examination paper based on learning outcomes, called Learning Outcome-based Question Examination paper Tool (LoQET). LoQET is proposed for assisting lecturer in Universiti Putra Malaysia for preparing examination paper based on programme outcomes and learning outcomes set in the teaching plan and assessment entries.
\end{abstract}

Keywords: outcome-based education, learning outcome, higher institution, assessment

\section{Introduction}

Outcome-based education (OBE) is an approach to education in which decisions about the curriculum are driven by the exit learning outcomes (LO) that the students should display at the end of the course (Davis, 2003). LO as 'being something that student can do now that they could not do previously' are changes in people as a result of learning experience (Watson, 2002). In contrast to traditional education, this approach particularly concerns on preparing students for life and work after graduate. OBE focuses on what the students can actually learn from the course and how to help students learn it and able to reproduce what was taught. For assessing the OBE, the chosen assessment methods should be able to measure how much and how well the students have learnt from the course. Therefore, the course teaching plan and course assessments are attentively created to support the intended learning outcomes that have been set out for the particular course.

OBE can serve as a benchmark to measure a success of a university (Mohayidin et al., 2008). Thus, the implementation of $\mathrm{OBE}$ is to ensure that the academic programmes, delivery systems, assessment methods and the graduates are of high quality. Therefore, there is a crucial need for supporting tools to assists universities in implementing OBE successfully in teaching and learning. Universiti Putra Malaysia (UPM) is one of the public universities in Malaysia that has implemented OBE approach in its teaching and learning strategy since year 2006 (CADe, 2009). Since then, UPM has upgraded its e-learning systems where many new modules have been introduced in the existing system in order to support OBE implementation. Thus far, the existing technology-based tools and efforts are mainly focus on activities related to administration work and student. However, efforts are continuously made by UPM to improve the system. As part of UPM community, we were motivated to propose a tool that is essential for implementing and achieving OBE. Hence, we proposed a tool called LOs-based Question Examination Tool (LoQET), which aims to help UPM's lecturer to compose questions examination paper align with learning outcomes and program outcome set in the course teaching plan and assessment entries. This tool is intended to give benefits to UPM's lecturers specifically and other universities that implementing OBE generally. Some of the significant benefits are:

- To reduce the amount of time in preparing examination paper, and emphasis should be given to assign each question with suitable learning outcomes 
- $\quad$ To improve the quality of examination paper by assigning each question with suitable learning outcomes that need to be achieved by the course.

This paper focuses on the development of LoQET prototype for the UPM. The activities conducted in this development are based on the common activities involved in software development methodologies. The remainder of the paper is organized as follows: In the following section, we provide a brief background of OBE and its implementation in UPM. Section 3, describes the activities conducted in developing LoQET. Section 4, discusses the findings based on the conducted development and evaluation. Finally, in Section 5, we draw conclusions and put forward future directions.

\section{Background}

Some overview of OBE and the implementation of OBE in Universiti Putra Malaysia (UPM) are given in this section.

\subsection{OBE Approach in Malaysia}

OBE is now being implemented in Malaysia at all levels of education especially at higher education institutions. In Malaysia, the paradigm shift to OBE is driven by the Malaysia Quality Agency (MQA) at the Ministry of Education, Malaysia (MoE). This agency is responsible for developing and implementing a national framework for education. The nine LOs as determined by the MoE which are Knowledge, Psychomotor/Practical/Technical Skills, Critical Thinking and Scientific Approach, Communication Skills, Social Skills/Teamwork/Responsibility, Life Long Learning and Information Management, Managerial and Entrepreneurial Skills, Professionalism, Values, Attitudes and Ethics and Leadership Skill. While, the seven soft-skills or known as Kemahiran Insaniah (KI) that need to be adopted in the program are Communication Skill, Critical Thinking and Problem Solving Skill, Teamwork Skill, Continuous Learning and Information Management, Entrepreneurship Skill, Moral and Professional Ethic, and Leadership Skill. To be in line with the ministry's objectives, most of public universities in Malaysia have made decision to adopt the OBE approach in their teaching and learning strategy. The significant efforts (e.g., Mohayidin et al., 2008; Jaafar et al., 2008; Shariff et al., 2011) have been continuously done to ensure that OBE is successfully implemented.

\subsection{OBE Implementation in UPM}

The MoE's learning outcomes become the base of UPM's programme outcome (PO). Program outcomes (PO) are the outcomes that students should have achieved by graduation time. UPM has emphasized that the curriculum design and development should be based on the specified outcomes. In which, each course in the particular programme must contribute to the achievement of the PO. Each course should determine the LO and KI that can be measured by each of the student. It was the decision of the curriculum planners that specified learning outcomes of each course (course LO) comprises of three learning domains; Cognitive, Psychomotor and Affective. In addition, the KIs should be embedded in the curriculum as part of UPM continuous efforts to ensure graduates able to adapt to any economic situations and seek for employment. Where, one to three KIs must be embedded in each course.

In order to know what the students are learning, and about the extent to which they are meeting the LO and KI, is via assessments. In UPM, the course assessment is continuous starting from first week until the end of semester. Essential information on student achievement is analysed at the end of the course learning process and assessment. The LOs can be assessed by using variety of assessment methods such as, test, final examination, quiz, assignment, project, and peer-assessment. As for paper based examination, the important information that should take into account in the paper is the question relationships with PO, LO, and its level.

\subsection{Technology-based OBE Supporting Tools in UPM}

UPM has provides a system called Student Information System or e-SMP in order to support activities in teaching and learning. The e-SMP offers few modules that facilitate lecturers, administrations, as well as students. Some of the main modules are student registration, course assessment, and course teaching plan. Furthermore, UPM has also plans and progressively develop more modules to be integrated to e-SMP in supporting the implementation of OBE. Since e-SMP provides a lot of facilities and information, thus, it motivates us to utilize the available information and data to help ensuring the implementation of OBE. At the same time, to enhance the e-SMP functionalities and help in reducing lecturer's efforts. In which, preparing examination paper is not only a repetitive and time consuming process, it is also challenging when the emphasis should been given to assign each question with suitable LO. Therefore, we propose a tool for assisting lecturer in preparing examination paper, called LOs-based Question Examination Tool (LoQET). The tool empowers the lecturer to generate effective and better quality examination paper in a very short span of time thus allowing the 
lecture to be more productive for other workloads. The tool allows generating a draft of an examination paper based on parameters (i.e., LO, competency level and assessment entry) which are available in LoQET's repository and e-SMP. The following section explains in detail the activities involved in LoQET development.

\section{LoQET Development Methodology}

The main activities carried out for developing LoQET are explained in this section.

\subsection{Analysis}

Before LoQET was designed, a diary study was conducted (Kamaruddin, et al., 2013) to determine the desired requirements and the limitations of existing system, e-SMP. The results of the study have shown the lecturers understanding and experiences when using the existing system in particularly the assessment module. The pilot data and experiences gathered from the participants have driven for the e-SMP functionalities to be improved and extended. One of the important aspects that we focused is on the lecturer's current practices. The results of the study have given us good insights for LoQET's requirements and design. LoQET's requirements are also gathered from informal interviews and discussions with system's stakeholders. An overview of LoQET is shown in Figure 1 to illustrate the boundary and external entities that interact with LoQET.

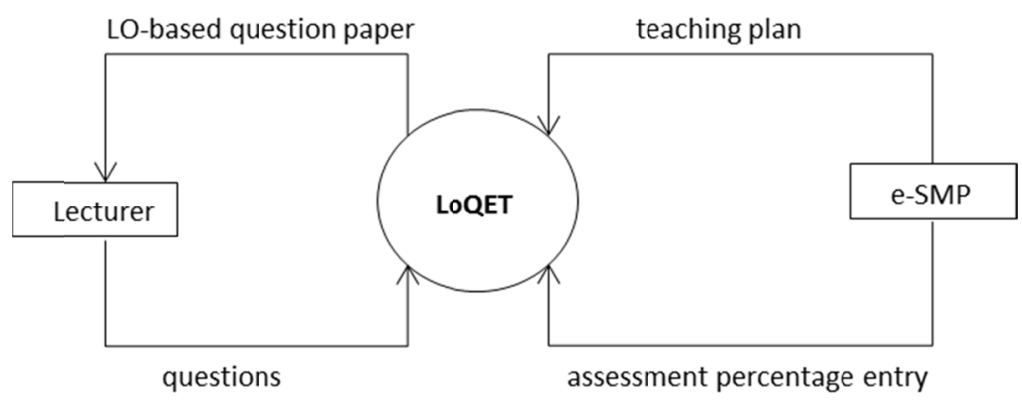

Figure 1. LoQET and external entities

The LoQET's main functional requirements are illustrated in a use case diagram as in Figure 2. The use case diagram shows the actors (i.e., Lecturer and e-SMP) that interact with LoQET functionalities (the use cases). The e-SMP will provide input regarding on course teaching plan and course assessment percentage entries. This input will be informed to the lecturer when she/he wants to compose a question paper for the particular course. Lecturer should also able to export question paper, reset or reorganize the question paper and view question paper. Other basic and common functionalities, such as create, retrieve, update, and delete are also offered.

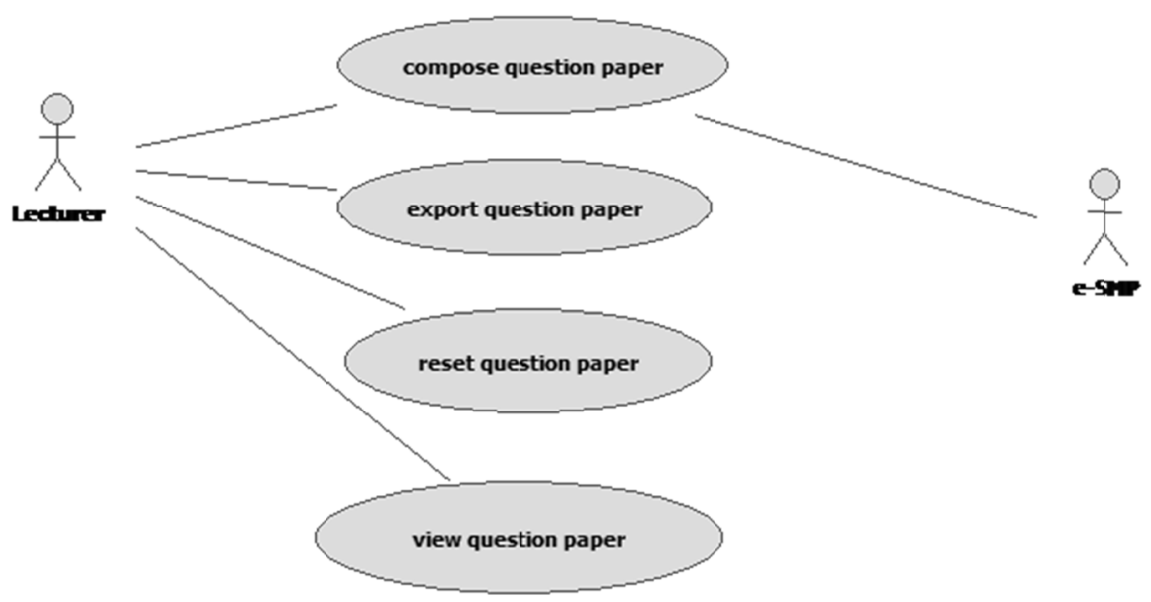

Figure 2. LoQET's use case diagram 
Initially, a paper-based prototype (as shown in Figure 3) is developed to illustrate the overview of the LoQET's functionalities. The paper-based prototype is also useful to generate ideas and to understand the business process. The gathered functional and non-functional requirements were documented in LoQET Requirements Specification. Some of the non-functional requirements stated concern about LoQET's performance, security and other quality attributes.

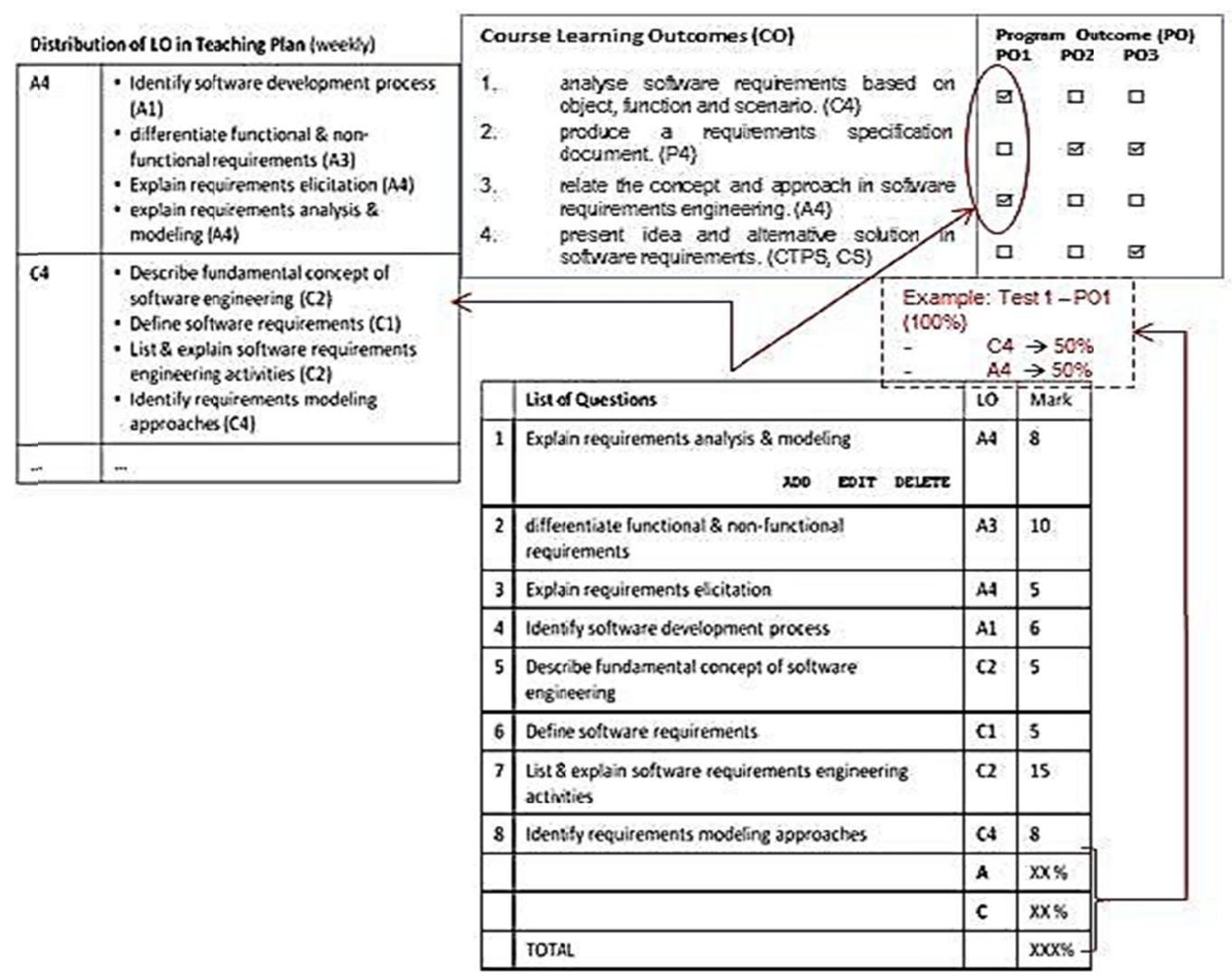

Figure 3. LoQET paper-based prototype

\subsection{Design and Implementation}

This section describes LoQET's architectural design, and components design to support the functionalities identified in the analysis phase. The architectural design of LoQET is separated into three layers shown in Figure 4.

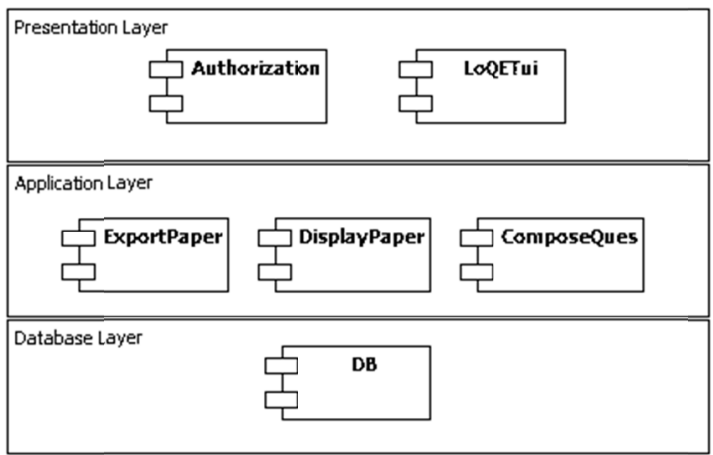

Figure 4. LoQET's architecture design 
Figure 5 shows related components developed in the LoQET and Table 1 describes in detail of each component.

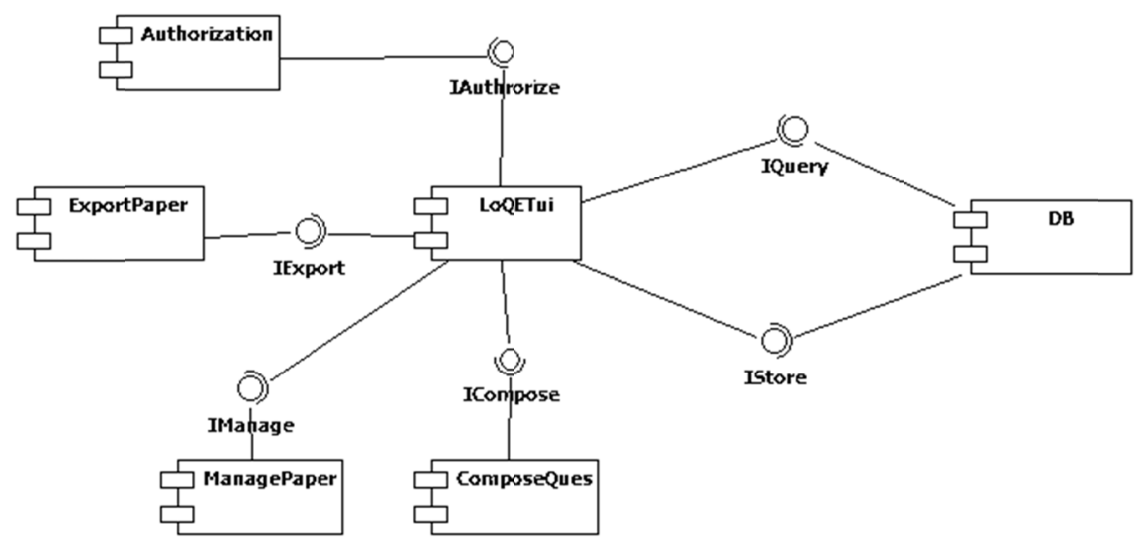

Figure 5. LoQET's component diagram

Table 1. Descriptions of LoQET's components

\begin{tabular}{|c|c|}
\hline Component & Description \\
\hline LoQETui & $\begin{array}{l}\text { The component should provide a user-friendly user interface design for } \\
\text { lecturers. }\end{array}$ \\
\hline ComposeQues & $\begin{array}{l}\text { The component should provide a main feature of LoQET to compose a set of } \\
\text { question, which aligns with learning outcomes and program outcomes. The } \\
\text { feature includes creating, deleting or editing these questions. }\end{array}$ \\
\hline ManagePaper & $\begin{array}{l}\text { The component should allow the lecturer to add, delete and edit an examination } \\
\text { paper details. }\end{array}$ \\
\hline ExportPaper & $\begin{array}{l}\text { The component should allow the lecturer to export composed exam paper in to } \\
\text { several formats such as pdf and txt. }\end{array}$ \\
\hline Authorization & The component should verify the user login. \\
\hline $\mathrm{DB}$ & $\begin{array}{l}\text { The component should store LoQET data onto tables (developed based on } \\
\text { classes) }\end{array}$ \\
\hline
\end{tabular}

Some of the implemented functionalities are shown in the screenshots (Figure 6 and 7). Figure 6 and Figure 7 show the implementation of use case for composing a question paper. User (i.e., lecturer) is required to select an assessment type from a list of assessment types obtained from e-SMP. The POs' mark distributions and LOs are also obtained from e-SMP based on the selected assessment type. A list of keywords will be displayed based on the selected LO. By having these features, it will ensure that each question will be assigned with learning outcome that need to be achieved by the course. In addition, user can give title for the question paper as reference. 


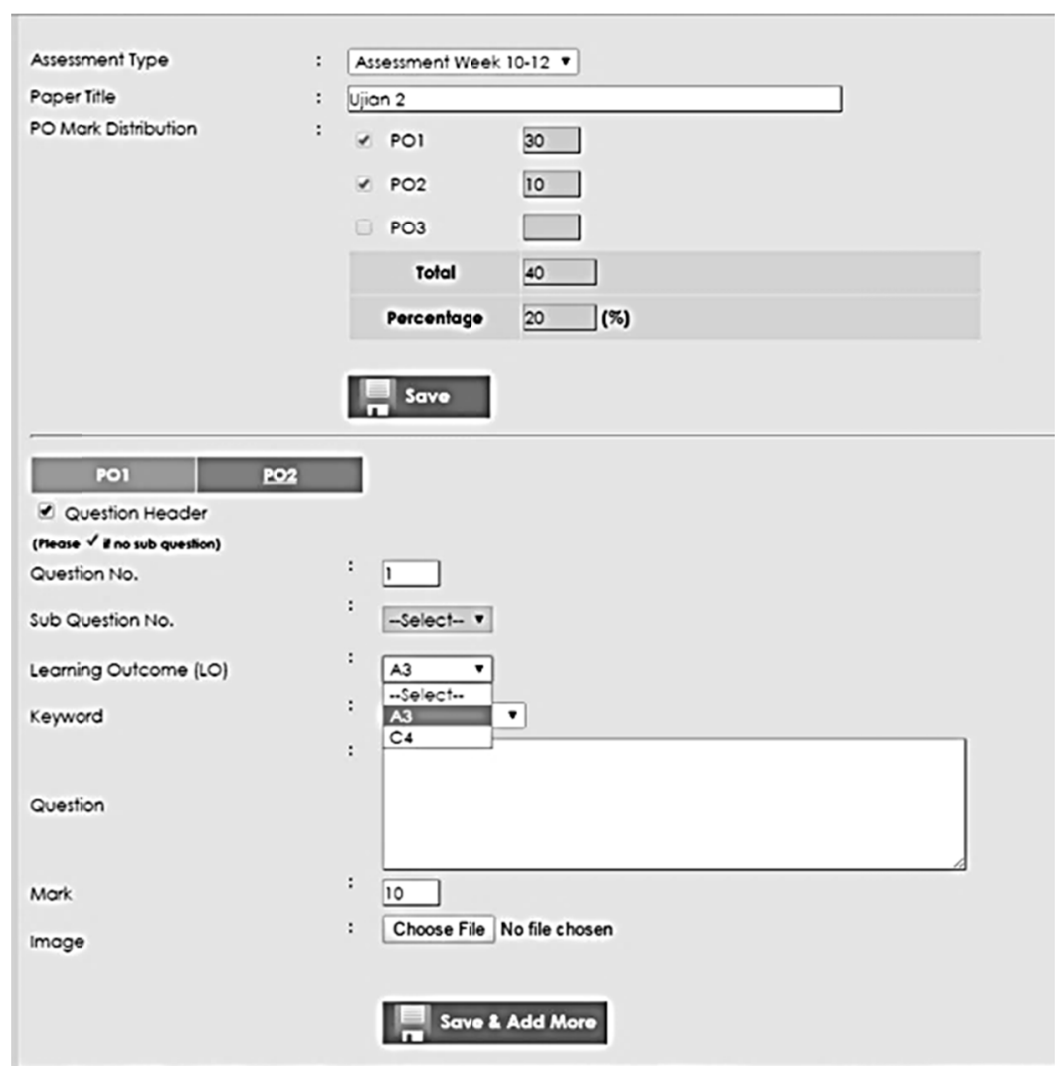

Figure 6. Compose a question paper (select LO)

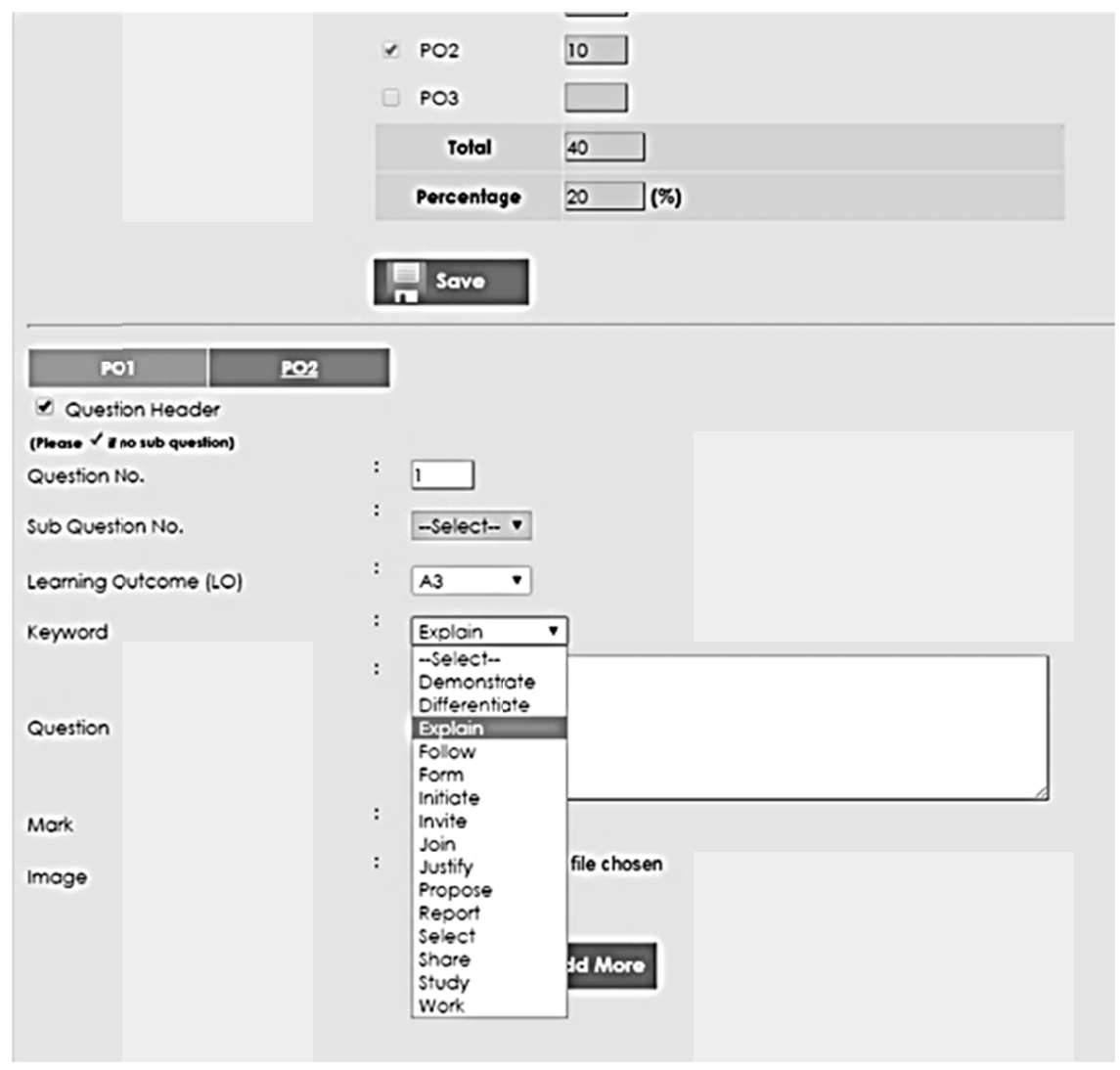

Figure 7. Compose a question (select keyword for the LO) 
Figure 8 shows a screenshot that displays a list of composed question papers and the implementation of other use cases. This screen provides user with features to view, copy, edit, and delete the composed paper. User is also able export the composed paper to Word format.

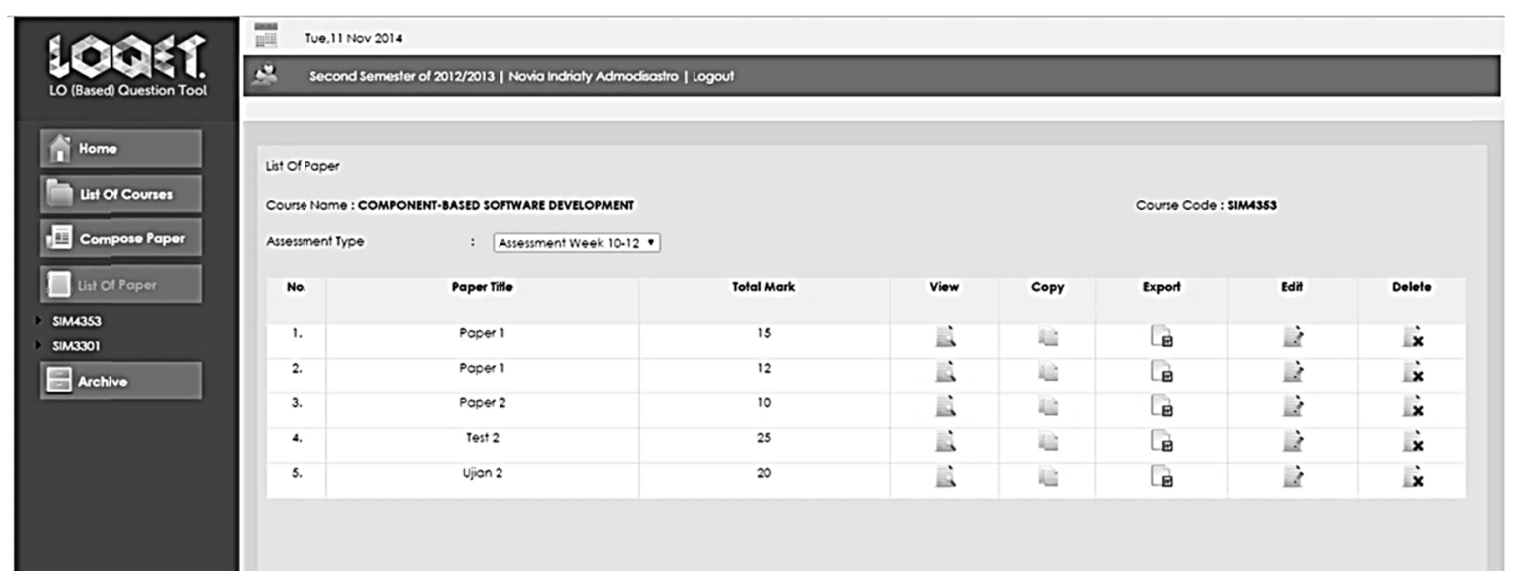

Figure 8. List of composed question papers

As an addition, user is provided with a monitoring feature. In which, user will be able to view a summary of the question paper as shown in Figure 9. This summary is useful to ensure the composed question paper is aligned with the POs and LOs for that course.

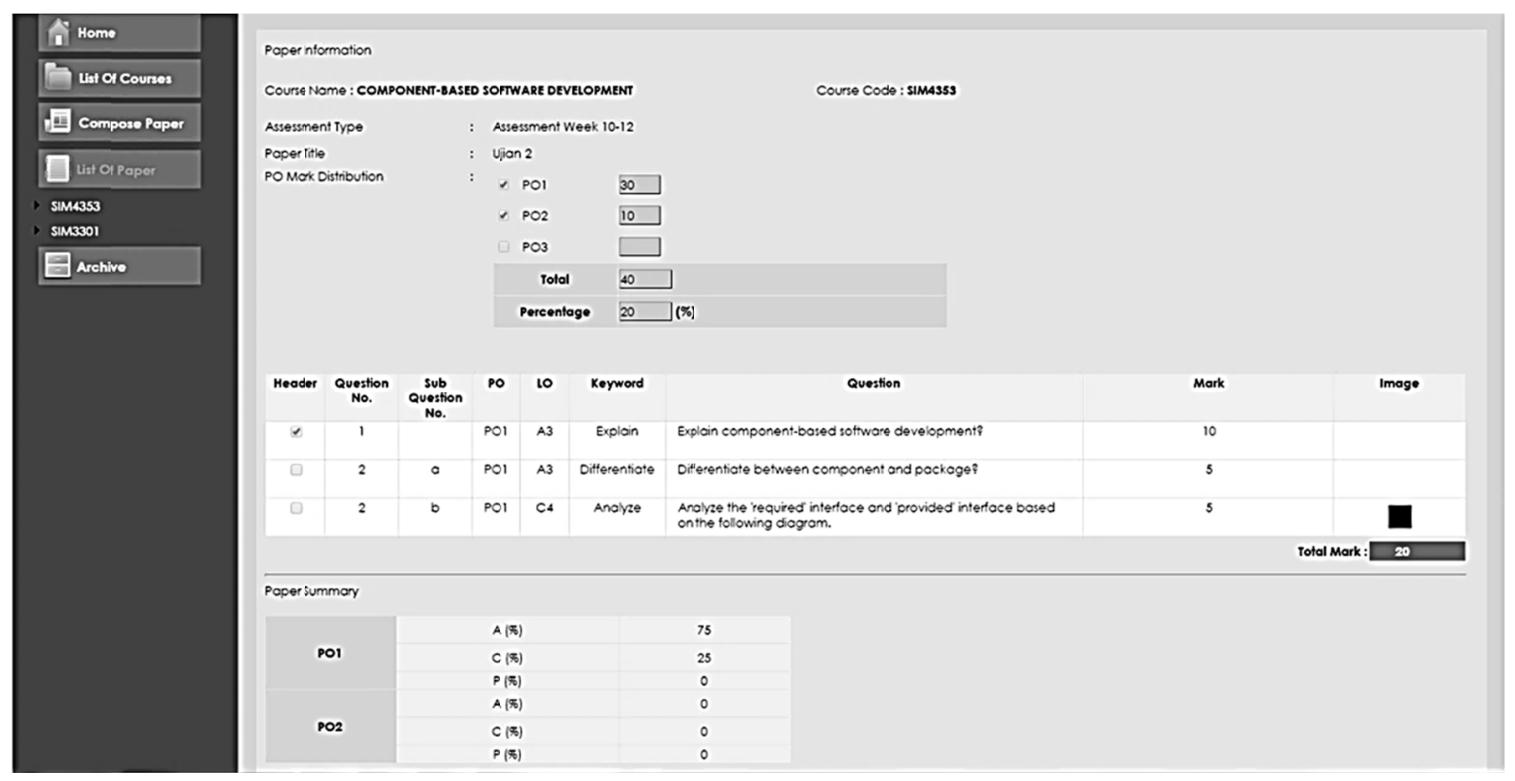

Figure 9. Summary of Question Paper

LoQET prototype is developed using the, PHP and MySQL software and running on Apache Tomcat server. The PHP is used for implementing the components in the presentation layer and application layer while, MySQL is for managing the database.

\section{Discussions}

During the study conducted in the analysis phase, our team has identified some features and design of e-SMP that need to be improved. Specifically in supporting LoQET's functionalities, in which, LoQET is mainly depend 
on data from e-SMP. Thus, some modification and adjustment to e-SMP database design need to be considered. The database design should be modifiable and expandable for future enhancement. The improvement that should be made is not only to support LoQET but also beneficial to other new modules that can be integrated with e-SMP in the future.

For LoQET development, the analysis and design stages were involving users is an iterative and rapid prototyping development cycle. In rapid prototyping, LoQET prototype are developed which can be quickly modified in line with users' evaluation and feedbacks. System testing and experts' review were also conducted to evaluate the final product. System testing aims to ensure that all the provided functionalities are functioning and implemented as in the proposed design. This testing was conducted by the developer and research team members. All the necessary modification required are fixed and done before the system is release for experts' review. While for the experts' review, LoQET was introduced and demonstrated to a group of lecturers as the group of experts. They were given for a week to evaluate the functionalities of the system. Suggestions for improvement were proposed both during the evaluation. The suggestions were regarding LoQET's functionalities and the interface design. The conclusion of the experts' review was that LoQET does help lecturer and provide basic facilities in preparing examination paper according to the POs and LOs set in e-SMP. However, they have also highlighted some functionality that need to be improved in order to achieve OBE objectives to the fullest. Given that LoQET is a prototype, thus, in order to deploy and integrate it in the real environment required a thorough study on the design, as well as software and hardware to be used.

The development of LoQET requires deep understanding on the business process and procedures of the domain. Thus, high involvement of lecturers, and knowledge and skill of the development team are essential. Agile development methodology seems a better choice for this particular situation. Based on our experience, we have spent a lot of time and effort at design stage. Even though the functional requirements are clear and firm, however, designing the system to fulfilling the functionalities is quite challenging. Feedbacks from users were important input for this stage. A few iterations of design have been made to improve the final design.

\section{Conclusion}

This paper describes the development of LOs-based Question Examination Tool (LoQET), for assisting lecturer in preparing examination paper based on POs and LOs set in the teaching plan and assessment entries. The main requirements and design elements are emphasized in the development activities. Some issues that need to be considered for the development are also discussed. Hopefully, those can act as guidelines on developing such system.

LoQET empowers lecturer to generate effective and better quality examination paper in a short span of time and allowing the lecturer to be more productive for other workloads. Our current and future work direction aims to develop a comprehensive assessment system that will facilitate implementation of OBE in higher institutions. The undergoing project is a system, called Examination Management System (EMaS), which aims to support supervision, execution, and evaluation of the examination paper. LoQET is part of EMaS and come together with other modules that aim to assist administration in managing and monitoring the implementation of $\mathrm{OBE}$ in the examination paper, and generate reports on student's performance and OBE achievement.

\section{Acknowledgements}

This project received support from Universiti Putra Malaysia.

\section{References}

CADe. (2009). Towards University of International Repute. Academia, Issue 1 (Jul-Dec 2009), 12-13.

CADe. (2012). Panduan Penyediaan Soalan: Kognitif, Psikomotor, dan Afektif. Retrieved from http://www.cade.upm.edu.my as on April 2012

Davis, M. H. (2003). Outcome-Based Education, Journal of Veterinary Medical Education, 30(3), 227-232. http://dx.doi.org/10.3138/jvme.30.3.258

Jaafar, M. S., Nordin, N. K., Wagiran, R., Aziz, A., Noor, M. J. M. M., Osman, M. R., . . Abdulaziz, F. N. A. (2008). Assessment Strategy for an Outcome Based Education. In proceeding ICEE 2008 International Conference on Engineering Education, Budapest, Hungary, 27-31 July

Kamaruddin, A., Hassan, S., Admodisastro, N. I., Che Pa, N., \& Baharom, S. (2013). E-Learning system usage based on user experience: A Case Study. In proceeding International Conference On Assessment for Higher Education Across Domains and Skills, 2013, 17-19 Dec, Kuala Lumpur (pp. 336-347).

Mohayidin, M. G., Suandi, T., Mustapha, G., Konting, M. M., Kamaruddin, N., Man, N. A., . . Abdullah, S. N. 
(2008). Implementation of outcome-Based Education in Universiti Putra Malaysia A Focus on Students' Learning Outcomes. International Education Studies, 1(4), 147-160.

Shariff, S. M., Johan, Z. J., \& Jamil, N. A. (2011). Developing Soft Skills and Learning Outcomes of Business Management Students in Project Management. In proceeding ICBEIA 2011 International Conference on Business, Engineering and Industrial Applications, 5-7 June 2011 (pp. 141-146). http://dx.doi.org/10.1109/ICBEIA.2011.5994229

Universiti Putra Malaysia. (2004). Module 1 Learning Outcomes Initiative, How to develop Outcome-Based Programme. Centre for Academic Development (CADe), UPM, accessed at www.cade.upm.edu.my as on April 2012.

Watson, P. (2002). The Role and Integration of Learning Outcomes into the Educational Process. Active Learning in Higher Education, 3(3), 205-219. http://dx.doi.org/10.1177/1469787402003003002

\section{Copyrights}

Copyright for this article is retained by the author(s), with first publication rights granted to the journal.

This is an open-access article distributed under the terms and conditions of the Creative Commons Attribution license (http://creativecommons.org/licenses/by/3.0/). 